\title{
Natalizumab-related anaphylactoid reactions in MS patients are associated with HLA class II alleles
}

\section{OPEN}

Belén de la Hera, MS Elena Urcelay, $\mathrm{PhD}$

David Brassat, MD

Andrew Chan, MD

Angela Vidal-Jordana, MD

Anke Salmen, MD

Luisa Maria Villar, MD

José Carlos Álvarez-

Cermeño, MD

Guillermo Izquierdo, MD

Oscar Fernández, MD

Begoña Oliver, $\mathrm{PhD}$

Albert Saiz, MD

Jose Ramón Ara, MD

Ana G. Vigo, PhD

Rafael Arroyo, MD

Virginia Meca, MD

Sunny Malhotra, $\mathrm{PhD}$

Nicolás Fissolo, PhD

Alejandro Horga, MD

Xavier Montalban, MD

Manuel Comabella, MD

Correspondence to

Dr. Comabella:

manuel.comabella@vhir.org

\section{See editorial}

Supplemental data at Neurology.org/nn

\section{ABSTRACT}

Objectives: We aimed to investigate potential associations between human leukocyte antigen (HLA) class I and class II alleles and the development of anaphylactic/anaphylactoid reactions in patients with multiple sclerosis (MS) treated with natalizumab.

Methods: HLA class I and II genotyping was performed in patients with MS who experienced anaphylactic/anaphylactoid reactions and in patients who did not develop infusion-related allergic reactions following natalizumab administration.

Results: A total of 119 patients with MS from 3 different cohorts were included in the study: 54 with natalizumab-related anaphylactic/anaphylactoid reactions and 65 without allergic reactions. HLA-DRB1*13 and HLA-DRB1*14 alleles were significantly increased in patients who developed anaphylactic/anaphylactoid reactions $\left(\mathrm{p}_{\mathrm{M}-\mathrm{H}}=3 \times 10^{-7}\right.$; odds ratio $[\mathrm{OR}]_{\mathrm{M}-\mathrm{H}}=8.96,95 \%$ confidence interval $[C l]=3.40-23.64)$, with a positive predictive value (PPV) of $82 \%$. In contrast, the HLA-DRB1*15 allele was significantly more represented in patients who did not develop anaphylactic/anaphylactoid reactions to natalizumab $\left(\mathrm{p}_{\mathrm{M}-\mathrm{H}}=6 \times 10^{-4} ; \mathrm{OR}_{\mathrm{M}-\mathrm{H}}=0.2,95 \% \mathrm{Cl}=0.08-0.50\right)$, with a PPV of $81 \%$.

Conclusions: HLA-DRB1 genotyping before natalizumab treatment may help neurologists to identify patients with MS at risk for developing serious systemic hypersensitivity reactions associated with natalizumab administration. Neurol Neuroimmunol Neuroinflamm 2014;1:e47; doi: 10.1212/ NXI.0000000000000047

\section{GLOSSARY}

$\mathbf{C I}=$ confidence interval; $\mathbf{H L A}=$ human leukocyte antigen; $\mathbf{M S}=$ multiple sclerosis; $\mathbf{N P V}=$ negative predictive value; $\mathbf{O R}=$ odds ratio; PPV = positive predictive value.

Similar to other biological agents, natalizumab, a highly effective therapy for multiple sclerosis (MS), can induce infusion-related hypersensitivity reactions. These reactions typically occur within 2 hours after infusion, with a peak at the second infusion, and range from urticaria, allergic dermatitis, and hives to more serious anaphylactic/anaphylactoid reactions in which treatment should be discontinued. ${ }^{1}$ The incidence of systemic hypersensitivity reactions classified as anaphylactoid or anaphylactic was reported to be $0.8 \%$ in the AFFIRM trial ${ }^{2}$ and ranged between $1.0 \%$ and $3.8 \%$ in more recent observational studies. ${ }^{3-6}$

An important number of drug hypersensitivity reactions are known to be mediated through interactions with human leukocyte antigen (HLA) molecules encoded within the major histocompatibility complex. ${ }^{7}$ Based on this, in the present study we investigated whether the

From the Department of Immunology (B.d.l.H., E.U., A.G.V.) and Department of Neurology, Multiple Sclerosis Unit (R.A.), Hospital Clínico San Carlos (IdISSC), Madrid, Spain; Pole des neurosciences et INSERM U1043 (D.B.), Université de Toulouse III, Hopital Purpan, Toulouse, France; Department of Neurology (A.C., A. Salmen), St. Josef-Hospital, Ruhr University, Bochum, Germany; Servei de Neurologia-

Neuroimmunologia (A.V.-J., S.M., N.F., A.H., X.M., M.C.), Centre d'Esclerosi Múltiple de Catalunya (Cemcat), Institut de Recerca Vall d'Hebron (VHIR), Hospital Universitari Vall d'Hebron, Universitat Autònoma de Barcelona, Spain; Departments of Neurology and Immunology (L.M.V., J.C.A.-C.), Hospital Universitario Ramón y Cajal, Instituto Ramón y Cajal de Investigacion Sanitaria, Madrid, Spain; Hospital Universitario Virgen Macarena (G.I.), Seville, Spain; Unidad de Gestión Clínica de Neurociencias (O.F., B.O.), Instituto de Biomedicina de Málaga (IBIMA), Hospital Universitario Regional de Málaga, Universidad de Málaga, Spain; Service of Neurology (A. Saiz), Hospital Clínic, Universitat de Barcelona and Institut dInvestigació Biomèdica August Pi i Sunyer (IDIBAPS), Barcelona, Spain; Department of Biochemistry, Molecular and Cellular Biology (J.R.A.), Science Faculty, University of Zaragoza, Spain; and Fundación de Investigación Biomédica (V.M.), Hospital Universitario de la Princesa, Madrid, Spain.

Go to Neurology.org/nn for full disclosures. Funding information and disclosures deemed relevant by the authors, if any, are provided at the end of the article. The Article Processing Charge was paid by the authors.

This is an open access article distributed under the terms of the Creative Commons Attribution-Noncommercial No Derivative 3.0 License, which permits downloading and sharing the work provided it is properly cited. The work cannot be changed in any way or used commercially. 
development of anaphylactic/anaphylactoid reactions in patients with MS treated with natalizumab was associated with particular HLA class I and class II alleles.

METHODS Patients and HLA typing. Inclusion criteria were patients with MS treated with natalizumab who developed anaphylactic/anaphylactoid reactions within 2 hours after infusion between the second and eleventh administrations of natalizumab, which motivated natalizumab suspension. Patients fulfilled the clinical criteria for the diagnosis of anaphylaxis promulgated in the World Allergy Organization anaphylaxis guidelines. ${ }^{8} \mathrm{~Pa}-$ tients with MS who did not develop anaphylactic/anaphylactoid reactions during natalizumab infusions were used as controls.

Genomic DNA was extracted from peripheral blood samples using standard methods. HLA genotyping was performed by means of the PCR-SSOP Luminex method using Lifecodes $H L A-A$, $H L A-B, H L A-D R B 1$, and $H L A-D Q B$ typing kits (Immucor Gamma Transplant Diagnostics, Inc., Heppignies,- Belgium) according to the manufacturer's instructions.

Statistical analysis. Statistical analysis was performed by using the SPSS 17.0 package (SPSS Inc., Chicago, IL). Comparisons of groups were analyzed using the $\chi^{2}$ test of a Fisher exact test (when expected values were below 5). To calculate combined odds ratios (ORs) and 95\% confidence intervals (CIs), we used the Cochran-MantelHaenszel method implemented in Review Manager RevMan v. 5.0 (The Nordic Cochrane Centre, Copenhagen, Denmark). $p$ values $<0.05$ were considered statistically significant. The Der Simonian and Laird random effects model was used according to the results of the tests of heterogeneity. A sensitivity analysis was performed to test the relative influence of each study on the results. Studies were sequentially dropped, and the effect on the change in the overall degree of heterogeneity was determined.

Standard protocol approvals, registrations, and patient consents. The study was approved by the corresponding local ethics committees, and all patients gave their informed consent.

RESULTS A total of 119 patients with MS belonging to 3 different cohorts (French, $\mathrm{n}=63$; Spanish, $\mathrm{n}=48$;
German, $\mathrm{n}=8$ ) were included in the study. A summary of demographic and main clinical characteristics of patients with MS who participated in the study is shown in table 1. Information on anti-natalizumab antibodies was available for 27 (50\%) of the 54 patients with MS who developed infusion-related anaphylactic/anaphylactoid reactions, and 22 patients $(81.5 \%)$ were positive for anti-natalizumab antibodies.

Tables e-1, e-2, and e-3 summarize the distribution of HLA alleles in all the patients with MS included in the study. The frequency of carriers of the HLA-DRB1*13 and HLA-DRB1*14 alleles (the latter in almost complete linkage disequilibrium with $\left.H L A-D Q B 1^{*} 05: 03\right)$ was significantly increased in patients who experienced anaphylactoid reactions compared to patients who did not develop drug-related allergic reactions (28/54 [52.0\%] vs 6/65 [10.5\%]; $p_{\mathrm{M}-\mathrm{H}}=3 \times 10^{-7} ; \mathrm{OR}_{\mathrm{M}-\mathrm{H}}[95 \% \mathrm{CI}]=8.96[3.40-$ 23.64]) (figure). In contrast, as depicted in the figure, the frequency of carriers of the HLA-DRBI*15 allele (in almost complete linkage disequilibrium with $\left.H L A-D Q B 1^{*} 06: 02\right)$ was significantly increased in the group of patients without allergic reactions to natalizumab compared to patients who developed anaphylactoid reactions (7/54 [13.0\%] vs 29/65 $[44.8 \%] ; p_{\mathrm{M}-\mathrm{H}}=6 \times 10^{-4} ; \mathrm{OR}_{\mathrm{M}-\mathrm{H}}[95 \% \mathrm{CI}]=$ $0.2[0.08-0.50])$. In the European population, the frequencies of the HLA-DRB1*15 and HLA$D R B 1 * 13 * 14$ alleles are $14 \%$ each.

Most probably these risk and protective HLA class II alleles conformed ancestral haplotypes with class I alleles, since the $H L A-D R B 1 * 13$ and $H L A-D R B 1 * 14$ alleles were frequently accompanied by $H L A-A^{*} 24$, and the $H L A-D R B 1^{*} 15$ allele by $H L A-A^{*} 03$ or $H L A$ $B^{*} 07$ (see tables e- 2 and e- 3 ). Nonetheless, the HLA class II alleles remained the best associated markers of

Table 1 Summary of demographic and baseline clinical characteristics of patients with MS treated with natalizumab included in the study

\begin{tabular}{|c|c|c|c|c|c|c|}
\hline \multirow[b]{2}{*}{ Characteristics } & \multicolumn{2}{|l|}{ France } & \multicolumn{2}{|l|}{ Spain } & \multicolumn{2}{|l|}{ Germany } \\
\hline & AR & No AR & AR & No AR & $A R$ & No AR \\
\hline N & 33 & 30 & 16 & 32 & 5 & 3 \\
\hline Age, $y^{a}$ & $35.8(6.3)$ & $37.5(9.0)$ & $35.8(8.3)$ & $38.1(7.1)$ & $33.4(4.8)$ & $37.7(8.7)$ \\
\hline Female/male (\% women) & $30 / 3$ (90.9) & $21 / 9$ (70.0) & $12 / 4(75.0)$ & 23/9 (71.9) & $4 / 1$ (80.0) & $2 / 1(66.7)$ \\
\hline Duration of disease, $y^{a}$ & $8.9(7.0)$ & $10.2(6.2)$ & $8.7(2.6)$ & $11.7(6.7)$ & 7.8 (3.2) & $6.7(4.5)$ \\
\hline EDSS score ${ }^{b}$ & $3.1(1.5-4.0)$ & $3.8(3.0-5.0)$ & $3.3(2.0-4.4)$ & $3.3(2.0-4.0)$ & $2.0(1.5-2.5)$ & $2.5(2.0-3.0)$ \\
\hline No. of relapses ${ }^{c}$ & $2.0(1.0)$ & $2.2(1.0)$ & $1.7(0.9)$ & $1.5(1.0)$ & $4.5(0.7)$ & $2.5(2.1)$ \\
\hline
\end{tabular}

Abbreviations: $A R=$ anaphylactic/anaphylactoid reaction; EDSS $=$ Expanded Disability Status Scale; MS = multiple sclerosis.

Data are expressed as mean (SD) unless otherwise stated.

${ }^{a}$ Refers to age and disease duration at treatment onset.

${ }^{b}$ Data are expressed as mean (interquartile range).

${ }^{\mathrm{C}}$ Refers to the number of relapses in the year before treatment onset. For the Germany cohort, information on relapses and EDSS is missing in 5 and 3 patients, respectively. 
Figure Meta-analysis showing the influence of HLA-DRB1*13/*14 and HLA-DRB1*15 in the development of anaphylactic/anaphylactoid reactions to natalizumab in the different study cohorts

A. HLA-DRB $1^{*} 13 /{ }^{*} 14$

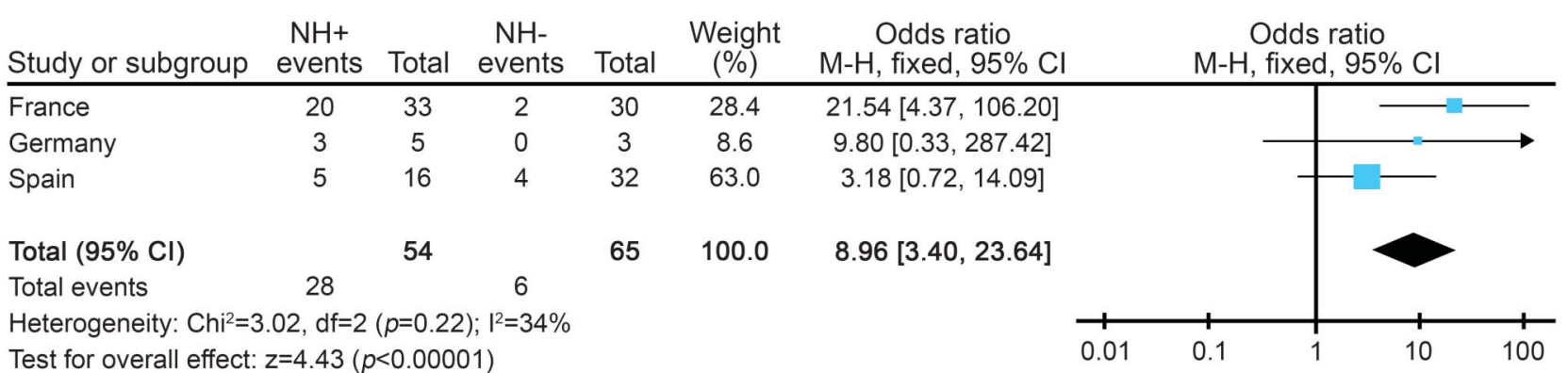

\section{B. HLA-DRB1*15}

\begin{tabular}{|c|c|c|c|c|c|c|c|c|c|}
\hline Study or subgroup & $\begin{array}{c}\mathrm{NH}+ \\
\text { events }\end{array}$ & Total & $\begin{array}{c}\mathrm{NH}- \\
\text { events }\end{array}$ & Total & $\begin{array}{c}\text { Weight } \\
(\%)\end{array}$ & $\begin{array}{c}\text { Odds ratio } \\
\mathrm{M}-\mathrm{H} \text {, fixed, } 95 \% \mathrm{Cl}\end{array}$ & \multicolumn{3}{|c|}{$\begin{array}{c}\text { Odds ratio } \\
\mathrm{M}-\mathrm{H} \text {, fixed, } 95 \% \mathrm{Cl}\end{array}$} \\
\hline France & 2 & 33 & 14 & 30 & 60.1 & $0.07[0.01,0.37]$ & - & & \\
\hline Germany & 1 & 5 & 3 & 3 & 13.7 & $0.05[0.00,1.56]$ & & & \\
\hline Spain & 4 & 16 & 12 & 32 & 26.2 & $0.56[0.15,2.12]$ & & & \\
\hline Total $(95 \% \mathrm{Cl})$ & & 54 & & 65 & 100.0 & $0.20[0.08,0.50]$ & & & \\
\hline Total events & 7 & & 29 & & & & & & \\
\hline Heterogeneity: $\mathrm{Chi}^{2}=4$ & $39, \mathrm{df}=2$ & $p=0.1$ & $;\left.\right|^{2}=54 \%$ & & & & - & & \\
\hline Test for overall effect: & $z=3.43(p$ & $=0.000$ & & & & & 0.01 & 10 & 100 \\
\hline
\end{tabular}

\section{Spanish cohort excluded}

Odds ratio $(95 \% \mathrm{Cl})$

$0.07[0.02,0.30]$

Heterogeneity: $\mathrm{Chi}^{2}=0.05, \mathrm{df}=1(p=0.82) ; \mathrm{I}^{2}=0 \%$

Test for overall effect: $z=3.60(p=0.0003)$

Meta-analysis showing the influence of HLA-DRB1*13/*14 (A) and HLA-DRB1*15 (B) in the development of anaphylactic/anaphylactoid reactions to natalizumab in the different study cohorts. Forest plots showing the overall data and data after eliminating heterogeneity by removing the Spanish cohort. $\mathrm{Cl}$ = confidence interval; $\mathrm{HLA}=$ human leukocyte antigen; $\mathrm{HN}+/ \mathrm{HN}-=$ patients who developed and did not develop anaphylactic/anaphylactoid reactions, respectively; $\mathrm{M}-\mathrm{H}=$ Mantel-Haenszel.

anaphylactic/anaphylactoid reactions to natalizumab, conferring the following positive and negative predictive values $(\mathrm{PPV} / \mathrm{NPV}): \mathrm{PPV}=0.82 / \mathrm{NPV}=0.69$ for the $H L A-D R B 1 * 13$ and *14, and PPV $=0.81 /$ $\mathrm{NPV}=0.57$ for the HLA-DRB1*15.

DISCUSSION Two types of infusion-related hypersensitivity reactions have been described in patients with MS treated with natalizumab: type I allergic reactions, which usually occur within 2 hours after infusion, ${ }^{1}$ and type III hypersensitivity reactions, which typically develop during several days. ${ }^{9}$ Type I hypersensitivity reactions include serious systemic anaphylactic/anaphylactoid, with an incidence that has been reported to be near $4 \%$ in some observational studies. ${ }^{3,6}$ When these hypersensitivity reactions are present, administration of natalizumab must be discontinued and patients should not be retreated.

Aiming to identify patients at risk for developing anaphylactic/anaphylactoid reactions to natalizumab, we performed HLA typing for class I and class II alleles in patients with MS from 3 different cohorts who were treated with natalizumab. The selection of the HLA region as the main target for genotyping was based on current evidence in the literature demonstrating significant associations between HLA and predisposition to adverse drug reactions. ${ }^{7}$ Drug hypersensitivity reactions are supposed to be mediated by inappropriate T-cell activation, and the key proteins implicated in these responses are the HLA molecules. Several models have been proposed to explain the mechanisms whereby small synthetic compounds are recognized by $\mathrm{T}$ cells in an HLAdependent manner, including the hapten/prohapten model, the altered peptide repertoire model, and the p-i model (pharmacologic interaction of drugs with immune receptors). ${ }^{10}$ Examples of drug-induced hypersensitivity reactions influenced by the HLA are the reactions to the reverse-transcriptase inhibitor abacavir and the xanthine oxidase inhibitor allopurinol, which are mediated by HLA class I alleles, and the reactions to the reverse-transcriptase inhibitor 
nevirapine and the first-line anticonvulsant carbamazepine, which are mediated by both HLA class I and class II alleles. ${ }^{7,10}$

Patients with MS carrying $H L A-D R B 1 * 13$ and $H L A-D R B 1^{*} 14$ alleles were at higher risk for developing natalizumab-related anaphylactic/anaphylactoid reactions compared to patients without allergic reactions, with an OR of 9 and a PPV of $82 \%$. On the other hand, the HLA-DRB1*15 allele, which is known to be the main genetic risk for MS, had a protective effect on the development of anaphylactic/anaphylactoid reactions, with an OR of 0.2 and a PPV of $81 \%$.

Neutralizing antibodies against natalizumab are usually present in patients having type I hypersensitivity reactions. ${ }^{11}$ In our study, $81 \%$ of the patients with MS who experienced anaphylactic/anaphylactoid reactions were positive for anti-natalizumab antibodies.

Based on these results, genotyping for the HLA-DRBI gene may be incorporated into clinical practice before initiating treatment with natalizumab to identify MS patients with increased (or decreased) risk for developing serious hypersensitivity reactions following IV administration of natalizumab. We suggest that patients with MS and HLA-DRB1*13 and HLA$D R B 1 * 14$ alleles be strictly monitored during natalizumab administration, maintaining a high index of suspicion for hypersensitivity reactions.

\section{AUTHOR CONTRIBUTIONS}

B. de la Hera: HLA genotyping, manuscript revision, statistical analysis and interpretation of the data. E. Urcelay: manuscript drafting and revision, study concept and design, contribution of patients and clinical data, statistical analysis and interpretation of the data. D. Brassat: manuscript revision, contribution of patients and clinical data, analysis and interpretation of the data. A. Chan: manuscript revision, contribution of patients and clinical data, analysis and interpretation of the data. A. VidalJordana: manuscript revision, contribution of patients and clinical data, analysis and interpretation of the data. A. Salmen: manuscript revision, contribution of patients and clinical data, analysis and interpretation of the data. L.M. Villar: manuscript revision, contribution of patients and clinical data, analysis and interpretation of the data. J.C. ÁlvarezCermeño: manuscript revision, contribution of patients and clinical data, analysis and interpretation of the data. G. Izquierdo: manuscript revision, contribution of patients and clinical data, analysis and interpretation of the data. O. Fernández: manuscript revision, contribution of patients and clinical data, analysis and interpretation of the data. B. Oliver: manuscript revision, contribution of patients and clinical data, analysis and interpretation of the data. A. Saiz: manuscript revision, contribution of patients and clinical data, analysis and interpretation of the data. J.R. Ara: manuscript revision, contribution of patients and clinical data, analysis and interpretation of the data. A.G. Vigo: HLA genotyping, manuscript revision, statistical analysis and interpretation of the data. R. Arroyo: manuscript revision, contribution of patients and clinical data, analysis and interpretation of the data. V. Meca: manuscript revision, contribution of patients and clinical data, analysis and interpretation of the data. S. Malhotra: manuscript drafting and revision, analysis and interpretation of the data. N. Fissolo: manuscript drafting and revision, analysis and interpretation of the data. A. Horga: manuscript revision, contribution of patients and clinical data. X. Montalban: manuscript revision, contribution of patients and clinical data, analysis and interpretation of the data. M. Comabella: manuscript drafting and revision, study concept and design, analysis and interpretation of the data, study supervision.

\section{STUDY FUNDING}

The "Red Española de Esclerosis Múltiple (REEM)" sponsored by the FEDER-FIS, FEDER-FIS PI13/0879 and the "Ajuts per donar Suport als Grups de Recerca de Catalunya," sponsored by the "Agència de Gestió d'Ajuts Universitaris i de Recerca" (AGAUR), Generalitat de Catalunya, Spain. The study was also funded with a FP7 grant "Best MS": Best Escalation Treatment in Multiple Sclerosis (MS), Grant agreement no: 305477. French patients were included in the BIONAT cohort funded by the French Ministry of Health (Projet Hospitalier de Recherche Clinique, PHRC 2008 (grant agreement no: 2008-005906-38 and clinicaltrials.org identifier NCT00942214) and the French MS Society (ARSEP 2007, 2008, 2010).

\section{DISCLOSURE}

B. de la Hera and E. Urcelay report no disclosures. D. Brassat has received funding from Biogen idec, Sanofi Genzyme, Teva, Merck Serono, Bayer, and Almirall and has received research support from French Ministry of Health, French Multiple Sclerosis Society, and European Union PF7 Marie Curie Action. A. Chan has served on the scientific advisory boards for Bayer Schering, Biogen Idec, Genzyme, Merck Serono, Novartis Pharma, Sanofi-Aventis, and Teva Neuroscience; has consulted for Bayer Schering, Biogen Idec, Genzyme, Merck Serono, Novartis, Sanofi-Aventis, and Teva Neuroscience; has received research support from Biogen Idec, Novartis Pharma, Genzyme, German Ministry for Education and Research, and Ruhr University Bochum; and was an expert consultant for Sanofi-Aventis. A. Vidal-Jordana has received speaker honoraria from Serono-Symposia, Teva, and Sanofi-Aventis and has received travel support from Novartis. A. Salmen has received speaker honoraria from Sanofi and Almirall Hermal GmbH. L.M. Villar holds a patent for a biomarker for selecting good responders to interferon- $\beta$ in MS, has been a consultant for Bayer and Biogen Idec, and received research support from Spanish Ministry of Economy and Competitiveness. J.C. Álvarez-Cermeño has served on the scientific advisory boards for Biogen Idec, Novartis, Genzyme, and Roche; received speaker honoraria from Biogen Idec, Novartis, Genzyme, and Teva; and received research support from Biogen Idec, Novartis, Bayer, Merck Serono, Carlos III Institute, and Spanish Ministry of Economy. G. Izquierdo has served on the scientific advisory boards for Biogen Idec, Bayer, Sanofi, Novartis, Merck, and Teva and has consulted for Sanofi, Merck, and Novartis. O. Fernández has served on the advisory boards for Biogen Idec, Bayer Schering, Merck Serono, Teva, Novartis, Actelion, Almirall, and Allergan and has received funding from Biogen Idec, Bayer Schering, Merck Serono, Teva, Novartis, Actelion, Almirall, and Allergan. B. Oliver reports no disclosures. A. Saiz has served on the advisory boards for Biogen Idec and Merck Serono; has received funding from Bayer Schering, Merck Serono, Biogen Idec, Sanofi-Aventis, Teva Pharmaceutical Industries, and Novartis; and has consulted for Bayer Schering, Merck Serono, Biogen Idec, Sanofi-Aventis, Teva Pharmaceutical Industries, and Novartis. J.R. Ara has received research support from Merck Espana, Novartis Espana, Biogen Idec, Sanofi Espana, and Teva. A.G. Vigo reports no disclosures. R. Arroyo has served on the advisory board for Teva, Biogen, Novartis, Merck Serono, Roche, Bayer, and Almirall and has received funding from Teva, Biogen, Novartis, Merck Serono, Bayer, and Almiral. V. Meca has served on the advisory board for Roche and has received funding from Biogen Idec, Novartis, Merck, and Teva. S. Malhotra has received research support from the "Red Española de Esclerosis Múltiple (REEM)" sponsored by the FIS, "Ajuts per donar Suport als Grups de Recerca de Catalunya," sponsored by the "Agència de Gestió d'Ajuts Universitaris i de Recerca," and Marie Curie Initial Training Network "UEPHA*MS." N. Fissolo reports no disclosures. A. Horga received research support from National Institute of Health Carlos III Spain. X. Montalban has served on the advisory boards for Novartis, Teva Pharmaceutical, Merck Serono, Biogen, Bayer Schering Pharma, GSK, Almirall, and Neurotech Pharma; has received funding from Novartis, Teva Pharmaceuticals, Merck Serono, Biogen, Bayer Schering Pharma, GSK, Almirall, and Neurotech Pharma; is on the editorial board for MS, Journal of Neurology, The International MS Journal, Revista Neurologia, and Therapeutic Advances in Neurological Disorders; has consulted for Bayer Schering Pharma, Biogen Idec, Merck Serono, Teva, Sanofi-Aventis, Novartis, Almirall, and Lilly; and has received research 
support from Multiple Sclerosis Foundation of Barcelona. M. Comabella has received speaker honoraria from Bayer Schering Pharma, Merck Sorono, Biogen Idec, Teva Pharmaceuticals, Sanofi-Aventis, and Novartis; is on the editorial board for Journal of Neuroimmunology and Journal of Clinical Immunology; and has received research support from Red Espanola de Esclerosis Multiple, Ajuts per donar Suport als Grups de Recerca de Catalunya, and Marie Curie Initial Training Network "UEPHA*MS." Go to Neurology.org/nn for full disclosures.

Received July 16, 2014. Accepted in final form October 13, 2014.

\section{REFERENCES}

1. Rudick RA, Panzara MA. Natalizumab for the treatment of relapsing multiple sclerosis. Biologics 2008;2:189-199.

2. Polman $\mathrm{CH}$, O'Connor PW, Havrdova E, et al. A randomized, placebo-controlled trial of natalizumab for relapsing multiple sclerosis. N Engl J Med 2006;345: 899-910.

3. Oturai AB, Koch-Henriksen N, Petersen T, Jensen PE, Sellebjerg F, Sorensen PS. Efficacy of natalizumab in multiple sclerosis patients with high disease activity: a Danish nationwide study. Eur J Neurol 2009;16:420-423.

4. Putzki N, Yaldizli O, Mäurer M, et al. Efficacy of natalizumab in second line therapy of relapsing-remitting multiple sclerosis: results from a multi-center study in German speaking countries. Eur J Neurol 2010;17:31-37.
5. Putzki N, Yaldizli O, Buhler R, Schwegler G, Curtius D, Tettenborn B. Natalizumab reduces clinical and MRI activity in multiple sclerosis patients with high disease activity: results from a multicenter study in Switzerland. Eur Neurol 2010;63:101-106.

6. Horga A, Castillo J, Rio J, et al. An observational study of the effectiveness and safety of natalizumab in the treatment of multiple sclerosis. Rev Neurol 2011;52:321-330.

7. Karlin E, Phillips E. Genotyping for severe drug hypersensitivity. Curr Allergy Asthma Rep 2014;14:418.

8. Sampson HA, Munoz-Furlong A, Campbell RL, et al. Second symposium on the definition and management of anaphylaxis: summary report-Second National Institute of Allergy and Infectious Disease/Food Allergy and Anaphylaxis Network symposium. J Allergy Clin Immunol 2006;117:391-397.

9. Hellwig K, Schimrigk S, Fischer M, et al. Allergic and nonallergic delayed infusion reactions during natalizumab therapy. Arch Neurol 2008;65:656-658.

10. Pavlos R, Mallal S, Phillips E. HLA and pharmacogenetics of drug hypersensitivity. Pharmacogenomics 2012;13: 1285-1306.

11. Calabresi PA, Giovannoni G, Confavreux C, et al. The incidence and significance of anti-natalizumab antibodies: results from AFFIRM and SENTINEL. Neurology 2007; 69:1391-1403. 


\title{
Neurology \\ Neuroimmunology \& Neuroinflammation
}

\author{
Natalizumab-related anaphylactoid reactions in MS patients are associated with HLA \\ class II alleles \\ Belén de la Hera, Elena Urcelay, David Brassat, et al. \\ Neurol Neuroimmunol Neuroinflamm 2014;1; \\ DOI 10.1212/NXI.0000000000000047
}

This information is current as of December 11, 2014

\begin{abstract}
Updated Information \&
Services

Supplementary Material

References

Permissions \& Licensing

Reprints

including high resolution figures, can be found at:

http://nn.neurology.org/content/1/4/e47.full.html

Supplementary material can be found at:

http://nn.neurology.org/content/suppl/2014/12/11/1.4.e47.DC1

This article cites 11 articles, 0 of which you can access for free at: http://nn.neurology.org/content/1/4/e47.full.html\#\#ref-list-1 its entirety can be found online at:

http://nn.neurology.org/misc/about.xhtml\#permissions

Information about ordering reprints can be found online: http://nn.neurology.org/misc/addir.xhtml\#reprintsus
\end{abstract}

Information about reproducing this article in parts (figures,tables) or in

Neurol Neuroimmunol Neuroinflamm is an official journal of the American Academy of Neurology.

Published since April 2014, it is an open-access, online-only, continuous publication journal. Copyright $\odot$ 2014 American Academy of Neurology. All rights reserved. Online ISSN: 2332-7812.

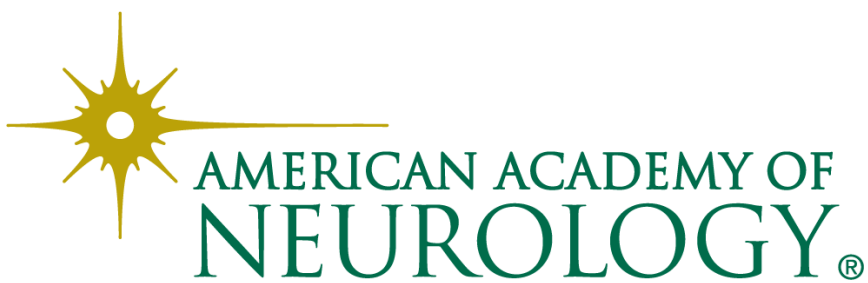

